\section{Evaluation of the stability and efficacy of a propofol-rocuronium mixture}

To the Editor:

Alternative strategies to reduce the onset time of nondepolarizing muscle relaxants, such as priming, ${ }^{1}$ administering large doses ${ }^{2}$ and using the timing principle $^{3,4}$ have not been completely succesful. We have used a propofol- rocuronium mixture for the rapid induction of anesthesia. First however, we tested whether a propofol-rocuronium mixture is stable.

UV spectra were obtained on a Shimadzu UV 2100 sec spectrophotometer $\left(10 \mathrm{mg} \cdot 100 \mathrm{~mL}^{-1}\right.$ in acetonitrile). A model 600 Waters pump was connected to a $200 \mu \mathrm{L}$ loop injector and a $\mu$ Bondapak $\mathrm{CN}$ column $(150 \mathrm{~mm} \times 3.9 \mathrm{~mm}$ internal diameter; Waters assoc. Milford, MA, USA). Model 481 Waters UV detector and Unicam ProGC Data Station were used. Compounds were detected at $220 \mathrm{~nm}$. The peak height was used for quantitation. The mobile phase was acetonitrile-water $(60: 40, \mathrm{v} / \mathrm{v})$. The flow rate, injection volume and detector response were $0.7 \mathrm{~mL} \cdot \mathrm{mL}^{-1}, 5 \mu \mathrm{L}$ and $15 \mu \mathrm{L}$ and $100 \mathrm{mV}$, respectively.

High pressure liquid chromatography (HPLC) method: standard stock solutions were freshly prepared with acetonitrile including $60 \mu \mathrm{g} \cdot \mathrm{mL}^{-1}$ rocuronium bromide and $100 \mu \mathrm{g} \cdot \mathrm{mL}^{-1}$ propofol. The external standard solutions were prepared with acetonitrile at a concentration of $60 \mu \mathrm{g} \cdot \mathrm{mL}^{-1}$ for rocuronium bromide and at a concentration of $100 \mu \mathrm{g} \cdot \mathrm{mL}^{-1}$ for propofol.

Standard propofol peak height with a standard deviation of 0.38 and standard rocuronium bromide peak height with a standard deviation of 0.25 were established. Peak heights of propofol and rocuronium bromide in propofol-rocuronium bromide (5:3) stock solutions were determined at zero, two, four, six, 18, 24,48 and $72 \mathrm{hr}$, respectively, in comparison to peak heights of the freshly prepared external standards at the same concentration level. We conclude that a 5:3 mixture of propofol and rocuronium bromide was stable up to $48 \mathrm{hr}$ after mixing. Propofol concentration in the mixtures stored at ambient temperature showed degradation $72 \mathrm{hr}$ after mixing. Propofol concentration in mixtures stored at $37^{\circ} \mathrm{C}$ showed degradation four hours after mixing.

After Ethic's Committee approval and patient written informed consent, 35 patients, ASA class I-II, undergoing elective surgery were included in this study. All patients received fentanyl $\mathrm{l} \mu \mathrm{g} \cdot \mathrm{kg}^{-1}$ followed by three minutes of preoxygenation. Anesthesia was then induced with the propofol $\left(2 \mathrm{mg} \cdot \mathrm{kg}^{-1}\right)$ - rocuro- nium $\left(0.6 \mathrm{mg} \cdot \mathrm{kg}^{-1}\right)$ mixture iv over $30 \mathrm{sec}$. All patients were intubated on the first attempt. The intubating conditions were evaluated using a score described by Viby-Mogensen. ${ }^{5}$ Intubating conditions at $60 \mathrm{sec}$ were determined as excellent in 26 patients and good in nine patients. We have not determined any adverse effect of this mixture.

We concluded that anesthesia induction with a propofol-rocuronium mixture provides excellent or good intubating conditions at $60 \mathrm{sec}$. It could be an effective and alternative technique for rapid induction of anesthesia.

Saffet Karaca MD

Ziya Salihoglu MD

Arzu Duran MSc

Sevim Rollas PhD

Istanbul, Turkey

\section{References}

1 Mehta MP, Choi WW, Gergis SD, Sokoll MD, Adolphson $A J$. Facilitation of rapid endotracheal intubations with divided doses of nondepolarizing neuromuscular blocking drugs. Anesthesiology 1985; 62: 392-5.

2 Ginsberg B, Glass PS, Quill T, Shafron D, Ossey KD. Onset and duration of neuromuscular blockade following high-dose vecuronium administration. Anesthesiology 1989; 71: 201-5.

3 Culling RD, Middaugh RE, Menk EJ. Rapid tracheal intubation with vecuronium: the timing principle. J Clin Anesth 1989; 1: 422-5.

4 Koh KF, Chen FG. Rapid tracheal intubation with atracurium: the timing principle. Report of investigation. Can J Anaesth 1994; 41: 688-93.

5 Viby-Mogensen J, Engbaek J, Eriksson LI, et al. Good clinical research practice (GCRP) in pharmacodynamic studies of neuromuscular blocking agents. Acta Anaesthesiol Scand 1996; 40: 59-74.

\section{Streptococcal meningitis after spinal anesthesia: report of a case}

To the Editor:

A 66 yr-old male underwent uneventful spinal anesthesia for right inguinal herniorhaphy. He had been taking medication for coronary arterial disease and hypertension.

During induction of spinal anesthesia the puncture site was found to be normal and sterilized with Povidon iodine (PI; Merkez Laboratuarlari Ilac San, Istanbul, Turkey). A sterile dressing pack and disposable needles 